\title{
Inclusão de alunos com deficiência nas aulas de Educação Física dos Colégios de Aplicação: a perspectiva de seus professores
}

Régis Henrique dos Reis Silva* Thiago Vaz Santiago**

Sônia Bertoni***

\section{Resumo}

Este artigo tem como objetivo analisar a situação vivenciada pelas Pessoas com Deficiência (PD) nas aulas de Educação Física dos Colégios de Aplicaçáo das Instituiçóes Federais de Ensino Superior (CAP/Ifes), na perspectiva dos professores dessa disciplina curricular, diante das políticas nacionais de educação especial. Para tanto, foram encaminhados questionários (semiestruturados) a 83 professores de Educação Física das instituiçóes supramencionadas, dos quais 22 foram efetivamente respondidos. Constatamos que nos atendimentos dos CAP/ Ifes as PD estão distante daquilo que preconiza as políticas nacionais de educação especial, haja vista que não estão garantidas as condições mínimas de permanência dessas pessoas naqueles colégios, mais precisamente nas aulas de Educação Física.

Palavras-chave: pessoas com deficiência, Educação Física, educação especial, Colégios de Aplicação.

Inclusion of students with disabilities in PE classes at the Colégios de Aplicação: the teachers' perspective

\begin{abstract}
This article sets out to analyze the experience of the disabled in PE classes at Colégios de Aplicação in Federal Institutes of Higher Education from the perspective of PE teachers, in the context of national policies for Special Education. Semi-structured questionnaires, of which 22 were effectively answered, were sent to 83 PE teachers at the above-mentioned institutes. It was seen that the services offered to the disabled fall far short of what national policies on Special Education demand, as these people are not given the minimum conditions for remaining on in these schools, and more specifically in PE classes.
\end{abstract}

Keywords: the disabled, PE, special education, Colégios de Aplicação

* Professor assistente do Centro de Ensino e Pesquisa Aplicada à Educação da Universidade Federal de Goiás (Cepae-UFG).E-mail: regishsilva@bol.com.br.

** Professor da rede estadual de ensino de Goiás. E-mail: thiago_shelter@hotmail.com.

*** Professora da Faculdade de Educação Física, da Universidade Federal de Uberlândia (UFU). E-mail: bertoni@faefi.ufu.br. 


\section{Introdução}

Este estudo tem como tema central a matrícula da Pessoa com Deficiência (PD) nos Colégios de Aplicação das Instituições Federais de Ensino Superior (CAP/Ifes).

Neste estudo, o termo pessoa com deficiência será utilizado para se referir à pessoa que tem "[...] impedimentos de longo prazo, de natureza física, mental ou sensorial que, em interação com diversas barreiras, podem ter restringida sua participação plena e efetiva na escola e na sociedade" (BRASIL, 2008, p. 9).

No Brasil, especialmente a partir dos anos 1980, observa-se um incremento na produção científica voltada para o tema da deficiência. Segundo Carmo (1991), isso se justifica pela preocupação que mundialmente passou a existir para com as PD, a partir de 1981, que foi considerado o Ano Internacional para as Pessoas Deficientes.

Entretanto, o direito da PD à educação já é objeto do aparato jurídico educacional brasileiro desde a "[...] Lei de Diretrizes e Bases da Educaçáo Nacional (LDBEN), Lei n. 4.024/61, que aponta o direito dos 'excepcionais' à educaçáo, preferencialmente dentro do sistema geral de ensino" (BRASIL, 2008, p. 2). Se bem que, efetivamente, as formulaçốes de políticas de educação especial no Brasil só ocorreram a partir de 1990, pois antes desse período eram caracterizadas por campanhas assistenciais e iniciativas isoladas do Estado.

É importante esclarecermos também que, neste estudo, a Educação Especial (EEs) será compreendida como uma modalidade de ensino que perpassa todos os níveis, etapas e modalidades e, integrada à proposta pedagógica da escola regular, realiza o atendimento educacional especializado a alunos com necessidades educacionais especiais (alunos com deficiência, transtornos globais de desenvolvimento e altas habilidades/superdotaçáo), além de orientar a organização de redes de apoio, a formação continuada, a identificação de recursos, serviços e o desenvolvimento de práticas colaborativas (BRASIL, 2008).

Nesse sentido, a primeira política nacional de destaque foi promulgada em 1994, intitulada Política Nacional de Educação Especial. Posteriormente, em 2003, o Ministério da Educação (MEC) iniciou a implementação do Programa Educação Inclusiva: direito à diversidade, cujo objetivo era 
[...] apoiar a transformação dos sistemas de ensino em sistemas educacionais inclusivos, promovendo um amplo processo de formação de gestores e educadores nos municípios brasileiros para a garantia do direito de acesso de todos à escolarização, à oferta do atendimento educacional especializado e à garantia da acessibilidade. (BRASIL, 2008, p. 4)

Recentemente, em janeiro de 2008, o governo brasileiro promulgou a Política Nacional de Educação Especial na perspectiva da Educação Inclusiva, que apresentou a Educação Inclusiva (EI) como um movimento mundial que age pela via política, cultural, social e pedagógica, e que fora desencadeada em defesa do direito de todos os alunos de estarem juntos, aprendendo e participando, sem nenhum tipo de discriminação (BRASIL, 2008).

De acordo com Brasil (2008, p. 1),

[...] a Educação Inclusiva constitui um paradigma educacional fundamentado na concepçáo de direitos humanos, que conjuga igualdade e diferença como valores indissociáveis, e que avança em relaçáo à idéia de eqüidade formal ao contextualizar as circunstâncias históricas da produção da exclusão dentro e fora da escola.

Segundo Silva, Sousa e Vidal (2008), atualmente são os princípios da integração e da inclusão que vêm norteando as discussóes na área educacional em congressos, seminários, eventos e publicações.

Nesse sentido, merecem serem citados os estudos e pesquisas da área de Educação Física que fizeram interface com o paradigma da inclusão escolar, a saber: Oliveira (2002), Sousa (2002), Souza (2003), Berto e Silva (2005), Bracht e Soares (2005), Chicon (2005), Cruz (2005 e 2007), Seabra Júnior (2006) e Falkenbach, Werle e Drexsler (2007).

A partir desses estudos e pesquisas, observamos que as dificuldades encontradas pelos professores de Educação Física diante da inclusão escolar são de cunho pedagógico, conceitual e/ou estrutural. Muitos dos professores abordados nos estudos citados justificam ser a falta de uma formação mais adequada (inicial e continuada) determinante para que as açôes pedagógicas não sejam satisfatórias frente ao trabalho com alunos que apresentem necessidades educacionais especiais no mesmo espaço daqueles ditos "normais".

Outro aspecto que ficou claro nos estudos foi a concepção de inclusão escolar dos diretores e dos professores como sendo uma obrigação prevista em leis e decretos; e náo como um novo paradigma que entende ser o acesso, 
a permanência e o ensino de qualidade direito de todos sem distinção e segregação em escolas especiais e/ou classes especiais. Tal fato revela-nos ser o paradigma da integração o norteador das açóes educacionais em geral.

A partir do estudo de Silva, Sousa e Vidal (2008), observamos que os indicadores da Educação Especial no Brasil, no período de 1996 a 2006, aumentaram. Por exemplo, nas redes municipais, o crescimento no número das matrículas do seu alunado foi de 235.462 (aproximadamente 800\%); nas redes estaduais, de 84.297 (aproximadamente 100\%); nas redes privadas, de 179.544 (mais de 230\%); nas escolas da rede federal de ensino, o aumento foi de apenas 179 (aproximadamente 20\%), e na soma geral, de 499.482 (aproximadamente 250\%).

Desses dados, podemos inferir que há um aumento significativo na matrícula do alunado da EEs nas escolas básicas brasileiras das redes públicas (municipais e estaduais) e privadas (geralmente filantrópicas), mas o mesmo náo ocorre com a rede pública federal.

Assim, no intuito de se fazer uma análise mais aprofundada desses dados, especialmente no tocante à análise situacional dos alunos com deficiência nas aulas de Educação Física da rede pública federal, desenvolvemos este estudo a fim de responder à seguinte questão central: Qual a situação vivenciada pelos alunos com deficiência nas aulas de Educação Física dos Colégios de Aplicação das Instituições Federais de Ensino Superior (CAP/ Ifes), na perspectiva dos professores dessa disciplina curricular?

Como objetivo geral, propomos analisar a situação vivenciada pelos alunos com deficiência nas aulas de Educação Física dos CAP/Ifes, na perspectiva dos professores dessa disciplina curricular, diante das políticas nacionais de EEs.

Os professores dos CAP/Ifes são servidores públicos federais geralmente concursados pelo Regime Jurídico Único, lotados nos CAP das Ifes, onde a maioria trabalha sob o regime de quarenta horas de trabalho semanal com dedicação exclusiva. Esses professores são doutores, mestres e pesquisadores envolvidos com o ensino nos níveis infantil, fundamental, médio e superior. E têm como funçóes o ensino, o desenvolvimento da pesquisa, a experimentação de novas práticas pedagógicas, a formação de professores, a criação, implementação e avaliação de novos currículos e capacitação de docentes (Cepae/UFG, 2009).

Nesse sentido, podemos inferir que os CAP/Ifes apresentam um potencial inovador importante na formulação de novas práticas pedagógicas, novos currículos, entre outras novidades acerca da Organização do Trabalho 
Pedagógico (OTP). Entendemos a OTP como o trabalho concretizado na escola, no interior da sala de aula, e entendemos que poderiam estar sendo mais bem exploradas as ideias e açóes que permeiam o projeto político-pedagógico, num contexto de transformação dos sistemas de ensino em sistemas educacionais inclusivos, como preconizam o Programa Educação Inclusiva: direito à diversidade, do MEC, e a Política Nacional de EEs na perspectiva da educação inclusiva.

Todavia, o que se verifica, pelo menos a partir dos números da matrícula do alunado da EEs na rede pública federal, não é isso. Por esse motivo, vimos a necessidade de uma análise situacional dos alunos com deficiência, na perspectiva dos professores de Educação Física dos CAP/Ifes, assim como consideramos a falta de informaçóes sistematizadas sobre essa questão um elemento complicador na superação dos inúmeros problemas enfrentados pelas PD, bem como para o avanço acadêmico-científico da área educacional brasileira.

\section{Procedimentos metodológicos}

Esta pesquisa caracteriza-se como um estudo de campo de caráter analítico-crítico e está delimitada a quinze CAP/Ifes, listados no quadro 01, no qual descrevemos o nome de cada colégio e a respectiva Ifes à qual se vincula, bem como a forma(s) de ingresso de alunos novatos na educação básica dessas instituiçóes, de acordo com o Condicap (CONSELHO..., 2007).

QUADRO 01: Nome dos Colégios de Aplicação e as Ifes às quais se vinculam, bem como as forma(s) de ingresso de alunos novatos na Educação Básica destas instituiçôes

\begin{tabular}{|l|l|l|l|}
\hline \multirow{2}{*}{ NOME DOS COLÉGIOS } & \multirow{2}{*}{ IFES } & \multicolumn{2}{|c|}{ FORMA(S) DE INGRESSO } \\
\cline { 3 - 4 } & & Ensino fundamental & Ensino médio \\
\hline 1. Colégio de Aplicação - CAP & UFRGS & \multicolumn{2}{|c|}{ Sorteio público de vagas } \\
\hline 2. Colégio de Aplicação - CAP & UFSC & \multicolumn{2}{|c|}{ Sorteio público de vagas } \\
\hline $\begin{array}{l}\text { 3. Colégio de Aplicação "João } \\
\text { XXIII" }\end{array}$ & UFJF & \multicolumn{2}{|c|}{ Sorteio público de vagas } \\
\hline $\begin{array}{l}\text { 4. Escola de Educação Básica } \\
\text { Eseba }\end{array}$ & UFU & \multicolumn{2}{|c|}{ Sorteio público de vagas } \\
\hline
\end{tabular}


144 Polyphonía, v. 22/1, jan./jun. 2011

(continuação)

\begin{tabular}{|c|c|c|c|}
\hline \multirow{2}{*}{ NOME DOS COLÉGIOS } & \multirow{2}{*}{ IFES } & \multicolumn{2}{|c|}{ FORMA(S) DE INGRESSO } \\
\hline & & Ensino fundamental & Ensino médio \\
\hline $\begin{array}{l}\text { 6. Centro de Ensino e Pesquisa } \\
\text { Aplicada à Educação - Cepae }\end{array}$ & UFG & \multicolumn{2}{|c|}{ Sorteio público de vagas } \\
\hline 7. Colégio de Aplicação - CAP & Ufac & \multicolumn{2}{|c|}{ Sorteio público de vagas } \\
\hline 8. Colégio de Aplicação - CAP & UFRR & \multicolumn{2}{|c|}{ Sorteio público de vagas } \\
\hline $\begin{array}{l}\text { 9. Núcleo de Educação Infantil } \\
\text { - NEI }\end{array}$ & UFRN & $\begin{array}{l}\text { Sorteio público de } \\
\text { vagas }\end{array}$ & Ordem de matrícula \\
\hline 10. Colégio de Aplicação - CAP & UFRJ & $\begin{array}{l}\text { Sorteio público de } \\
\text { vagas }\end{array}$ & $\begin{array}{c}\text { Exame de } \\
\text { nivelamento e } \\
\text { sorteio público }\end{array}$ \\
\hline 11. Colégio Universitário - Colun & UFMA & $\begin{array}{l}\text { Sorteio público de } \\
\text { vagas }\end{array}$ & $\begin{array}{c}\text { Exame de Língua } \\
\text { Portuguesa e } \\
\text { Matemática }\end{array}$ \\
\hline 12. Colégio de Aplicação - CAP & UFPE & \multicolumn{2}{|c|}{ Exame de Língua Portuguesa e Matemática } \\
\hline 13. Colégio de Aplicação - Codap & UFS & \multicolumn{2}{|c|}{ Exame de Língua Portuguesa e Matemática } \\
\hline $\begin{array}{l}\text { 14. Colégio de Aplicação - } \\
\text { Coluni }\end{array}$ & UFV & \multicolumn{2}{|c|}{ Exame de seleção } \\
\hline $\begin{array}{l}\text { 15. Núcleo Pedagógico Integrado } \\
\text { - NPI }\end{array}$ & UFPA & \multicolumn{2}{|c|}{ Exame de seleção } \\
\hline
\end{tabular}

Sobre os CAP/Ifes, cabe-nos esclarecer que optamos por não trabalhar com o núcleo de desenvolvimento infantil da UFSC, pois privilegiamos, neste estudo, as análises referentes ao ensino fundamental e médio, bem como a Eseba/UFU e o Centro Pedagógico da UFMG, que não possuem ensino médio, e o Coluni/UFV, que não possui ensino fundamental.

Foram encaminhados questionários (semiestruturados) para 83 professores de Educação Física, que atuavam nos colégios supramencionados no primeiro semestre de 2008, dos quais 22 (26,5\%) foram efetivamente respondidos.

No quadro 02, podemos visualizar os CAP/Ifes aos quais estáo vinculados os 22 professores de Educação Física, que responderam aos questionários enviados. 
QUADRO 02: Demonstrativo do número de professores de Educação Física participantes da pesquisa e os colégios aos quais estâo vinculados

\begin{tabular}{|l|c|c|}
\hline NOME DO COLÉGIO & $\begin{array}{c}\text { N. DE } \\
\text { PROFESSORES } \\
\text { DE ED. FÍSICA }\end{array}$ & $\begin{array}{c}\text { N. DE PROFESSORES QUE } \\
\text { RESPONDERAM AOS } \\
\text { QUESTIONÁRIOS }\end{array}$ \\
\hline 1. CAP - UFRGS & 8 & 7 \\
\hline 2. Eseba - UFU & 6 & 6 \\
\hline 3. Cepae - UFG & 5 & 4 \\
\hline 4. CAP - UFPE & 4 & 2 \\
\hline 5. CAP - Ufac & 3 & 2 \\
\hline 6. CAP - UFJF & 7 & 1 \\
\hline
\end{tabular}

As perguntas dos questionários foram construídas objetivando fornecer um diagnóstico da situação vivenciada pelos alunos com deficiência nas aulas de Educação Física, diante das políticas nacionais de Educação Especial.

Para realizarmos a análise dos questionários, verificamos o percentual e o conteúdo das respostas apresentadas pelos professores.

\section{Resultados}

Nesta parte do trabalho, apresentamos os resultados da análise dos questionários respondidos pelos professores de Educação Física dos seis CAP/Ifes. Para tanto, dividimo-los em três subitens, a saber: 1) conceito de inclusão escolar; 2) garantia do direito de acesso e fluxo de matrículas; e 3) oferta de atendimento educacional especializado e acessibilidade.

\section{Conceito de inclusão escolar}

Nos questionários encaminhados aos professores, perguntamos qual o conceito de inclusáo escolar, com o intuito de analisar como eles compreendem as políticas nacionais de EEs, principalmente o Programa Educação Inclusiva: direito à diversidade, e a Política Nacional de EEs na perspectiva da Educação Inclusiva. Eles estão em sintonia com o movimento mundial pela educação inclusiva, a qual é resultante do avanço do discurso elaborado 
por organismos internacionais em torno da noção de direitos humanos, bem como das pressóes dos grupos e movimentos sociais interessados na defesa dos direitos das pessoas deficientes.

Dos 22 respondentes, onze professores (50\%) definem a inclusão como participação efetiva dos alunos da EEs nas atividades escolares, a partir de estratégias pedagógicas e adaptaçóes que possibilitem o trabalho com esses alunos, juntamente com os demais, respeitando as diferenças. Esse grupo de respostas comprova a preocupação com a adaptação da escola e dos materiais pedagógicos, bem como com a necessidade de reconhecimento e respeito para com as diferenças.

Quatro professores (18\%) responderam que a inclusão visa incluir todos, indistintamente, com acesso a tudo que o ambiente escolar oferece, respeitando a diversidade humana. Isso demonstra que esses professores compreendem a inclusão como algo que supera o tempo, espaço e conhecimento da sala de aula e se refere a toda escola.

Nas nossas análises, também verificamos que três professores (14\%) definem a participação de todos na escola, participação entendida apenas no nível das relaçóes sociais dos alunos da EEs com os demais alunos.

A reorganização escolar (seus tempos, espaços, normas e relaçóes, além da forma do trato do conhecimento, a partir de outras bases epistemológicas, ontológicas e axiológicas) foi abordada por dois professores (9\%), como a principal mudança exigida pela inclusão escolar. Ela deve se sustentar em mudanças estruturais da organização social, política e econômica de todo o mundo.

Dos 22 respondentes, um professor $(4,5 \%)$ conceitua a inclusão como uma perspectiva ética que possibilita a qualidade da interação social e do trabalho pedagógico na escola.

E apenas um professor (4,5\%) não respondeu à questão sobre o conceito de inclusão escolar.

A partir desses dados, podemos analisar que a maioria dos professores de Educação Física dos CAP/Ifes compreende a inclusão escolar como um conjunto de estratégias pedagógicas e adaptaçóes nas atividades escolares que possibilitam o trabalho com os alunos atendidos pela EEs, juntamente com os demais, respeitando as diferenças. Isso demonstra certa sintonia com a política nacional de EEs, pelo menos acerca do direito de todos aprenderem juntos, sem nenhum tipo de discriminação. 
Nesse sentido, acreditamos que as adaptaçôes são importantes e necessárias, pois possibilitam que as PD tenham seu acesso e permanência garantidos no âmbito escolar, assim como viabiliza, entre outras coisas, o convívio social delas com outras pessoas. Entretanto, por si só, não garantem a essas pessoas e às demais um ensino de qualidade, capaz de garantir aos alunos a apreensão dos conteúdos historicamente produzidos pelo ser humano, e que está sob a responsabilidade da escola veiculá-los às novas geraçôes, bem como a superação dos estigmas e preconceitos que, historicamente, acompanham os alunos da EEs.

Mais precisamente, concordamos com as respostas de dois professores de Educação Física, que compreendem a inclusão escolar como um movimento que poderá possibilitar uma nova visão de homem, mundo e sociedade, desde que a escola reestruture a organização do seu trabalho pedagógico, ao mesmo tempo em que também ocorram mudanças estruturais na organização social mais ampla, pois ambas estão intrinsecamente relacionadas.

\section{Garantia do direito de acesso e fluxo de matrículas}

Na sequência, procuramos identificar quantos alunos com deficiência os professores de Educação Física tinham em suas turmas, bem como o ano escolar em que esses alunos estavam matriculados, qual(is) o(s) tipo(s) de deficiência apresentada(s) por eles e como se dava a frequência e participação deles nas aulas de Educação Física.

No quadro 03, apresentamos os dados obtidos:

QUADRO 03: Demonstrativo do número de alunos com deficiência e o(s) tipo(s) de deficiência apresentada(s) por eles, conforme o ano escolar

\begin{tabular}{|l|c|c|c|c|c|c|c|}
\hline ANOS DO ENSINO & N. DE ALUNOS & \multicolumn{6}{|c|}{ TIPOS DE DEFICIÊNCIA } \\
\cline { 5 - 8 } $\begin{array}{l}\text { FUNDAMENTAL E } \\
\text { ENSINO MÉDIO }\end{array}$ & DEFICIÊNCIA & DM & DA & DV & DF & DMU & OUTROS \\
\hline $\begin{array}{l}1^{\circ} \text { Ano/Ensino } \\
\text { Fundamental }\end{array}$ & 2 & & & 1 & & & 1 \\
\hline $\begin{array}{l}2^{\circ} \text { Ano/Ensino } \\
\text { Fundamental }\end{array}$ & 1 & & & & 1 & & \\
\hline
\end{tabular}

(continua) 
(continuação)

\begin{tabular}{|c|c|c|c|c|c|c|c|}
\hline \multirow{2}{*}{$\begin{array}{l}\text { ANOS DO ENSINO } \\
\text { FUNDAMENTAL E } \\
\text { ENSINO MÉDIO }\end{array}$} & \multirow{2}{*}{$\begin{array}{l}\text { N. DE ALUNOS } \\
\text { COM } \\
\text { DEFICIÊNCIA }\end{array}$} & \multicolumn{6}{|c|}{ TIPOS DE DEFICIÊNCIA } \\
\hline & & DM & DA & DV & DF & DMU & OUTROS \\
\hline $\begin{array}{l}3^{\circ} \text { Ano/Ensino } \\
\text { Fundamental }\end{array}$ & 3 & & & & 2 & & 1 \\
\hline $\begin{array}{l}4^{\circ} \text { Ano/Ensino } \\
\text { Fundamental }\end{array}$ & 4 & 2 & 2 & & & & \\
\hline $\begin{array}{l}5^{\circ} \text { Ano/Ensino } \\
\text { Fundamental }\end{array}$ & 3 & & & & & 3 & \\
\hline $\begin{array}{l}6^{\circ} \text { Ano/Ensino Fun- } \\
\text { damental }\end{array}$ & 6 & 3 & & & & 1 & 2 \\
\hline $\begin{array}{l}7^{\circ} \text { Ano/Ensino } \\
\text { Fundamental }\end{array}$ & 0 & & & & & & \\
\hline $\begin{array}{l}8^{\circ} \text { Ano/Ensino } \\
\text { Fundamental }\end{array}$ & 1 & & & 1 & & & \\
\hline $\begin{array}{l}9^{\circ} \text { Ano/Ensino } \\
\text { Fundamental }\end{array}$ & 1 & 1 & & & & & \\
\hline $1^{\circ}$ Ano/Ensino Médio & 0 & & & & & & \\
\hline $2^{\circ}$ Ano/Ensino Médio & 0 & & & & & & \\
\hline $3^{\circ}$ Ano/Ensino Médio & 0 & & & & & & \\
\hline TOTAL & 21 & 6 & 2 & 2 & 3 & 4 & 4 \\
\hline
\end{tabular}

O levantamento realizado junto aos 22 professores de Educação Física dos seis CAP/Ifes sobre a quantidade de alunos com deficiência e o(s) tipo(s) de deficiência apresentada(s) por eles, conforme o ano escolar, nos revelou que:

1. Há apenas 21 alunos com deficiência matriculados nas instituiçóes em que os professores ministram aulas.

2. O maior número de alunos com deficiência encontra-se nos seis primeiros anos do ensino fundamental (90,5\%).

3. O número de alunos com deficiência nos três últimos anos do ensino fundamental é inexpressivo $(9,5 \%)$ e inexistente no Ensino Médio (0\%). 
Quanto à frequência e participação dos alunos com deficiência nas aulas de Educação Física, apenas um professor (4,5\%) afirmou que um aluno $(5 \%)$ não participa de suas aulas, pois estava com restrições médicas. Esse aluno encontrava-se matriculado no $5^{\circ}$ ano do ensino fundamental e tinha diagnóstico de deficiência múltipla.

Diante desses dados e com base nas informaçóes do quadro 01, podemos afirmar que, no plano formal dos seis CAP/Ifes, cujos professores de Educação Física responderam aos questionários deste estudo, cinco já universalizaram as possibilidades de acesso dos alunos novatos por meio de sorteio público de vagas. Entretanto, os sorteios ainda não viabilizaram um crescimento efetivo no número de alunos com deficiência matriculados nessas instituições, visto que há registros de apenas 21 matrículas.

Além disso, outro dado importante é a maior concentração de alunos com deficiência nos seis primeiros anos do ensino fundamental, enquanto, nos três últimos anos dessa fase escolar, esses números são inexpressivos e inexistentes no ensino médio. Isso, no nosso entendimento, está relacionado com a OTP das instituiçóes, especialmente com a padronização do currículo escolar e dos tempos e espaços de aprendizagem, que aumentam as expectativas e as comparaçóes avaliativas entre os alunos, conforme eles avançam nos anos escolares e se aproximam do ensino médio e dos processos seletivos para o ingresso no ensino superior. Isso prejudica a formação desses indivíduos, bem como a garantia de permanência e sucesso deles durante o processo de escolarização.

\section{Oferta de atendimento educacional especializado e acessibilidade}

Dos 22 professores de Educação Física, quatorze deles (64\%) não têm nenhum aluno com deficiência matriculado em suas turmas, enquanto oito professores (36\%) têm alunos com deficiência matriculados em suas turmas.

Perguntamos aos professores que tem alunos com deficiência em suas turmas se os locais onde são ministradas as aulas são adaptados e se há materiais pedagógicos de Educação Física adaptados para eles. Segundo esses professores, os locais dessas aulas não são adaptados, assim como não há materiais pedagógicos de Educação Física adaptados para os alunos com deficiência. 
$\mathrm{Na}$ sequência, perguntamos aos mesmos professores se os conteúdos das aulas de Educação Física, ministrados para os alunos com deficiência, são os mesmos ministrados para os demais alunos da turma. De acordo com os oito professores, são, sim, os mesmos conteúdos.

Questionamos os professores que têm alunos com deficiência em suas turmas se os alunos com deficiência participam de todos os momentos das aulas. Em caso negativo, em quais atividades e por quais motivos eles não participam.

Sete professores $(87,5 \%)$ responderam que os alunos com deficiência participam de todos os momentos das aulas de Educação Física, e apenas um professor $(12,5 \%)$ afirmou que eles não participam de todos os momentos da aula. Segundo esse professor, os alunos com deficiência não participam das atividades de reflexôes e debates. Quanto ao motivo da não participação deles nessas atividades, ele não respondeu.

Preocupa-nos o fato de esses alunos não participarem de todos os momentos das aulas, principalmente das atividades de reflexóes e debates, pois são nelas, geralmente, que a compreensão do real passa do plano concreto (empírico imediato) para o concreto pensado (empírico pensado), passando pela mediação da abstração e apropriação coletiva do conhecimento. Em outras palavras, é quando ocorrem os saltos qualitativos e o desenvolvimento dos alunos.

Questionamos os professores que têm alunos com deficiência em suas turmas se os alunos com deficiência que participam das aulas de Educação Física recebem algum tipo de atendimento, fora do horário de aula, para auxiliar na superação de possíveis dificuldades encontradas em sala, e, em caso afirmativo, quais são os locais desses atendimentos. Esses dados estão expostos no quadro 04 .

Ao analisarmos esse quadro, constatamos que:

Dos oito professores respondentes, sete $(87,5 \%)$ afirmaram que os alunos com deficiência recebem algum tipo de atendimento, fora do horário de aula, no intuito de superar eventuais dificuldades encontradas por eles.

Apenas um professor (12,5\%) respondeu que não existe nenhum tipo de atendimento aos alunos com deficiência fora do horário de aula. 
QUADRO 04: Demonstrativo do número e percentual de respostas fornecidas pelos professores de Educação Física sobre os tipos de atendimentos aos alunos com deficiência fora do horário de aula, bem como o local de atendimento

\begin{tabular}{|c|c|c|c|c|}
\hline RESPOSTAS & N. $=8$ & PORCENTAGEM & $\begin{array}{c}\text { TIPO DE } \\
\text { ATENDIMENTO } \\
\text { FERECIDO }\end{array}$ & $\begin{array}{c}\text { LOCAL DE } \\
\text { ATENDIMENTO }\end{array}$ \\
\hline Sim & 7 & 87,5 & $\begin{array}{l}\text { A- Médico, psico- } \\
\text { lógico e pedagógi- } \\
\text { co (3) } \\
\text { B- O próprio pro- } \\
\text { fessor de Educação } \\
\text { Física (3) } \\
\text { C- Projeto Pedagó- } \\
\text { gico Complemen- } \\
\text { tar da Eseba/UFU, } \\
\text { Fonoaudiólogo, } \\
\text { atividades esporti- } \\
\text { vas (1) }\end{array}$ & $\begin{array}{l}\text { A- Própria escola, } \\
\text { mas em horário di- } \\
\text { ferente das aulas } \\
\text { - Atendimento rea- } \\
\text { lizado pelos próprios } \\
\text { professores (3) } \\
\text { B- Setor de Apoio } \\
\text { Psicopedagógico } \\
\text { Social da ESEBA/ } \\
\text { UFU (2) } \\
\text { C- Própria escola, } \\
\text { mas em horário di- } \\
\text { ferente das aulas (3) } \\
\text { - Atendimento reali- } \\
\text { zado por psicólogos } \\
\text { e pedagogos da pró- } \\
\text { pria escola (2) } \\
\text { D- Própria escola, } \\
\text { mas no horário Re- } \\
\text { creio- Atendimento } \\
\text { realizado pelo pro- } \\
\text { fessor de Educação } \\
\text { Física (1) }\end{array}$ \\
\hline Não & 1 & 12,5 & $\begin{array}{l}\text { D- A escola náo } \\
\text { oferece esse tipo de } \\
\text { atendimento (1) }\end{array}$ & \\
\hline
\end{tabular}

Quanto ao tipo e local de atendimento, o quadro 04 nos fornece os seguintes dados:

1. Os atendimentos são realizados na própria escola, na maioria deles em horários diferentes das aulas $(87,5 \%)$, sendo feitos por equipe formada por pedagogos (geralmente, psicopedagogos), psicólogos, fonoaudiólogos e médicos (50\%) e/ou pelos próprios professores de Educação Física (37,5\%). 
Procuramos saber quais as três principais dificuldades enfrentadas pelos professores que ministram aulas de Educação Física para alunos com deficiência.

No quadro 05, apresentamos os dados obtidos.

QUADRO 05: Demonstrativo do número e percentual de respostas fornecidas pelos professores dos CAP/Ifes sobre as principais dificuldades enfrentadas por eles ao ministrarem aulas de Educação Física para alunos com deficiência, por número de prevalências

\begin{tabular}{|c|c|c|}
\hline $\begin{array}{c}\text { DIFICULDADES } \\
\text { ENFRENTADAS PELOS } \\
\text { PROFESSORES }\end{array}$ & PORCENTAGEM & N. DE PREVALÊNCIAS \\
\hline $\begin{array}{l}\text { A- Acesso aos ambientes físicos } \\
\text { da escola }\end{array}$ & 17 & 5 \\
\hline B- Falta de formação especializada & 17 & 5 \\
\hline $\begin{array}{l}\text { C- O relacionamento das PD } \\
\text { com os demais colegas }\end{array}$ & 13 & 4 \\
\hline D- Falta de materiais específicos & 10 & 3 \\
\hline $\begin{array}{l}\text { E- Tempo para atendimentos } \\
\text { individualizados }\end{array}$ & 7 & 2 \\
\hline $\begin{array}{l}\text { F- Dificuldade de compreensáo } \\
\text { por parte dos alunos deficientes }\end{array}$ & 7 & 2 \\
\hline $\begin{array}{l}\text { G- Resistência dos professores ao } \\
\text { trabalhar com as PD }\end{array}$ & 3 & 1 \\
\hline $\begin{array}{l}\text { H- Falta apoio da comunidade } \\
\text { escolar e de políticas públicas }\end{array}$ & 3 & 1 \\
\hline $\begin{array}{l}\text { I- Diagnóstico das dificuldades } \\
\text { das PD }\end{array}$ & 3 & 1 \\
\hline $\begin{array}{l}\text { J- Falta apoio de profissionais } \\
\text { especializados }\end{array}$ & 3 & 1 \\
\hline K- Os limites da OTP da escola & 3 & 1 \\
\hline $\begin{array}{l}\text { L- A recusa do aluno em partici- } \\
\text { par das aulas }\end{array}$ & 3 & 1 \\
\hline $\begin{array}{l}\text { M- A família que não aceita as } \\
\text { dificuldades do filho }\end{array}$ & 3 & 1 \\
\hline $\begin{array}{l}\text { N-A falta de um trabalho multi- } \\
\text { disciplinar }\end{array}$ & 3 & 1 \\
\hline O- Não tem dificuldades & 3 & 1 \\
\hline
\end{tabular}


Como podemos observar no quadro 05 , várias foram as dificuldades elencadas pelos professores quando se trata de ministrar aulas para alunos com deficiência. Entre as cinco mais frequentes, aparecem: em primeiro lugar, as dificuldades de acesso dos alunos aos espaços físicos (acessibilidade); também, a falta de formação especializada dos professores, com $17 \%$ das respostas cada uma delas; em terceiro lugar, o relacionamento entre os alunos com 13\%; em quarto lugar, a falta de materiais específicos, com 10\%; e, em quinto lugar, tempo para atendimentos individualizados e dificuldade de compreensão por parte dos alunos deficientes, com 7\% das respostas cada uma delas.

Questionamos também os professores sobre as três principais dificuldades que os alunos com deficiência enfrentam ao participarem das aulas de Educação Física.

Esses dados são apresentados no quadro 06.

QUADRO 06: Demonstrativo do número e percentual de respostas fornecidas pelos professores sobre as principais dificuldades enfrentadas pelos alunos com deficiência ao participarem das aulas de Educação Física

\begin{tabular}{|l|c|c|}
\hline $\begin{array}{c}\text { DIFICULDADES ENFRENTADAS } \\
\text { PELOS ALUNOS COM } \\
\text { DEFICIÊNCIA, SEGUNDO OS } \\
\text { PROFESSORES }\end{array}$ & PORCENTAGEM & $\begin{array}{c}\text { N. DE } \\
\text { PREVALÊNCIAS }\end{array}$ \\
\hline $\begin{array}{l}\text { Estigmas e preconceitos por parte dos } \\
\text { colegas. }\end{array}$ & 27 & 8 \\
\hline $\begin{array}{l}\text { B- Dificuldades de compreensão e } \\
\text { execução das atividades propostas em sala. }\end{array}$ & 17 & 5 \\
\hline $\begin{array}{l}\text { C- Falta de formaçáo especializada dos } \\
\text { professores. }\end{array}$ & 13 & 4 \\
\hline $\begin{array}{l}\text { D- Autoexclusão - por serem } \\
\text { discriminados, os alunos com deficiência } \\
\text { evitam participar das aulas. }\end{array}$ & 10 & 3 \\
\hline $\begin{array}{l}\text { E- Acessibilidade - acesso aos espaços } \\
\text { físicos da escola. }\end{array}$ & 7 & 2 \\
\hline $\begin{array}{l}\text { F- Falta de apoio de profissionais } \\
\text { especializados. }\end{array}$ & 7 & 2 \\
\hline $\begin{array}{l}\text { G- Constrangimento diante de atividades } \\
\text { que não conseguem realizar. }\end{array}$ & 7 & 2 \\
\hline
\end{tabular}


(continuação)

\begin{tabular}{|l|c|c|}
\hline $\begin{array}{c}\text { DIFICULDADES ENFRENTADAS } \\
\text { PELOS ALUNOS COM } \\
\text { DEFICIÊNCIA, SEGUNDO OS } \\
\text { PROFESSORES }\end{array}$ & PORCENTAGEM & $\begin{array}{c}\text { N. DE } \\
\text { PREVALÊNCIAS }\end{array}$ \\
\hline $\begin{array}{l}\text { H- Os professores não dão atenção aos } \\
\text { problemas dos alunos. }\end{array}$ & 3 & 1 \\
\hline I- Relacionamentos com os outros colegas. & 3 & 1 \\
\hline $\begin{array}{l}\text { J- Falta de cooperação nos ambientes } \\
\text { escolares. }\end{array}$ & 3 & 1 \\
\hline $\begin{array}{l}\text { K- Padronização do tempo e espaços } \\
\text { escolares. }\end{array}$ & 3 & 1 \\
\hline
\end{tabular}

Ao analisar o quadro 06, observamos que várias são as dificuldades enfrentadas pelos alunos com deficiência nas aulas de Educação Física na perspectiva dos professores. Entre as cinco mais frequentes, aparecem: em primeiro lugar, os estigmas e os preconceitos dos colegas, com $27 \%$ das respostas; em segundo lugar, às dificuldades de compreensão e de execução das atividades propostas em sala, com 17\%; em terceiro lugar, a falta de formação especializada dos professores, com 13\%; em quarto lugar, a autoexclusão dos alunos com deficiência por serem discriminados, com 10\%; e, em quinto lugar, a acessibilidade; a falta de apoio de profissionais especializados; e o constrangimento sofrido pelos alunos com deficiência, diante de atividades que não conseguem realizar, com $7 \%$ cada uma delas.

A seguir, expomos, a partir dos dados descritos, uma breve síntese dos principais resultados referentes à oferta de atendimento especializado e à acessibilidade:

1. Segundo os professores de Educação Física, eles não fazem adaptaçóes nos conteúdos, não trabalham com materiais pedagógicos adaptados nem dispóem de espaços físicos adaptados nas escolas, assim como a maioria deles $(87,5 \%)$ responderam que os alunos com deficiência participam de todos os momentos das aulas.

2. A maioria dos alunos com deficiência $(87,5 \%)$ recebe algum tipo de atendimento, os quais são realizados na própria escola, na maioria deles em horários diferentes das aulas $(87,5 \%)$, sendo feito por equipe formada por pedagogos (geralmente, psicopedagogos), 
psicólogos, fonoaudiólogos e médicos (50\%) e/ou pelos próprios professores de Educação Física (37,5\%).

3. De acordo com os professores de Educação Física, as principais dificuldades enfrentadas por eles, ao ministrarem aulas aos alunos com deficiência, estão relacionadas à falta de acessibilidade aos espaços físicos das escolas (17\%) e à falta de formaçáo especializada dos professores (17\%), além do relacionamento entre os alunos (13\%), da falta de materiais específicos $(10 \%)$ e do tempo para atendimentos individualizados (7\%).

4. As principais dificuldades que os alunos com deficiência enfrentam ao participarem das aulas de Educação Física, segundo os professores dessa disciplina curricular, são os estigmas e os preconceitos dos colegas (27\%); as dificuldades de compreensão e de execução de algumas atividades propostas em sala (17\%); a falta de formação especializada dos professores (13\%); a autoexclusão, por serem discriminados pelos colegas (10\%); além da falta de acessibilidade aos espaços físicos da escola, da falta de apoio de profissionais especializados e do constrangimento sofrido pelos alunos com deficiência, diante de atividades que não conseguem realizar (7\%).

Diante desses dados, avaliamos que, embora a maioria dos alunos com deficiência receba algum tipo de atendimento, apenas na metade dos casos ele é realizado por profissionais com algum tipo de especialização. Além do que esses atendimentos da forma com que vêm sendo realizados nos parecem distantes daquilo que preconizam as políticas nacionais de educação especial, haja vista que não estão garantidas as condiçóes mínimas de acesso e permanência da PD nos CAP/Ifes, mais precisamente nas aulas de Educação Física. Isso ficou evidente quando observamos a diminuição do número de alunos com deficiência nos anos escolares mais avançados.

Também corrobora com essa interpretação o fato de os professores de Educação Física afirmarem que não fazem adaptações nos conteúdos, não trabalham com materiais pedagógicos adaptados, nem dispóem de espaços físicos adaptados nas escolas. Em outras palavras, embora os professores reconheçam a necessidade de adaptaçóes na escola, bem como a formulação de novas estratégias pedagógicas como forma de garantir o acesso, a permanência e o sucesso dos alunos com deficiência no processo de escolarização, quando conceituaram a inclusão escolar, de fato não as fazem. 
Enfim, a partir das análises das respostas dos professores de Educação Física, podemos inferir que o que vem sendo realizado pelos CAP/ Ifes, no tocante a atendimento educacional especializado e acessibilidade, ainda é insuficiente, além de estarem praticando o que alguns autores da área educacional vêm conceituando como inclusão-excludente (FREITAS, 2002). Isto é, os alunos com deficiência (e da classe trabalhadora) estão lá, mas efetivamente não participam e/ou não aprendem, pois, como os professores afirmaram, eles não se sentem preparados, falta apoio de profissionais especializados e faz-se necessário garantir a acessibilidade dos alunos com deficiência aos espaços físicos da escola.

Acreditamos que isso ocorra não por conta da falta de "vontade" e/ou "incompetência" dos educadores e profissionais dos CAP/Ifes, mas por força de uma política que impóe uma lógica escolar sobre a outra, como indica o título do artigo de Carmo (2001), "Inclusão escolar: roupa nova em corpo velho", pois os resultados desta pesquisa são muito similares aos que foram encontrados por Oliveira (2002), Sousa (2002), Souza (2003), Berto e Silva (2005), Bracht e Soares (2005), entre outros. Embora tenham analisado realidades diferentes, basicamente identificaram os mesmos problemas de cunho pedagógico, conceitual e/ou estrutural para se garantir a inclusão e sucesso escolar das PD na rede regular de ensino.

\section{Consideraçóes finais}

Entendemos que esta pesquisa de campo oportunizou-nos verificar o baixo número de alunos com deficiência matriculados nos CAP/Ifes, bem como um pouco da realidade situacional dessas pessoas na visão dos professores de Educação Física dessas instituições.

Nesse sentido, os professores relataram suas concepções de inclusão escolar, bem como algumas dificuldades por eles vivenciadas diante das políticas nacionais de educação especial. Dentre essas dificuldades, destacamos a falta de formaçáo específica desses educadores acerca do tema em questáo, o que compromete a compreensão e a análise crítica sobre o movimento mundial pela educação inclusiva.

Compromete a compreensão, pois muitas vezes os educadores limitam a educação inclusiva a adaptaçóes arquitetônicas e dos conteúdos escolares. Isso de modo a valorizar, em alguns casos, a socialização dos alunos 
com deficiência em detrimento da apreensão por parte destes do conhecimento historicamente produzido pelo ser humano e veiculado pela escola. Podemos reconhecer, nos limites do modo de produção do capital, um avanço o fato de haver PD matriculadas nos CAP/Ifes e participando das aulas de Educação Física. Também o é a educação inclusiva, visto que há pouco menos de três décadas as PD sequer eram aceitas nas escolas regulares, o que demonstra, portanto, tratar-se de um movimento contraditório, no qual as atuaçóes dos movimentos sociais estão levando a conquistas não previstas pela política educacional e social em questão.

Compromete a criticidade, pois, embora a educação inclusiva levante questóes acerca das "diferenças" e possibilite o acesso da PD à escola regular, trata-se de uma política que se articula a um conjunto de prescrições neoliberais elaboradas, a partir do Consenso de Washington, que ocorreu em meados dos anos 1980, onde os países do primeiro mundo definiram o futuro da economia mundial, as políticas de desenvolvimento e especificamente o papel do Estado (VIDAL, 2006), que passou a adotar um modelo político de Estado mínimo, para as políticas sociais, e máximo, para as políticas econômicas. Portanto, trata-se, segundo Sanfelice (2006), de uma política compensatória, dentre outras, avaliada por indicadores quantitativos mais do que qualitativos.

Assim sendo, se esse movimento não possibilitar aos educadores e à sociedade em geral ir à raiz dos problemas sociais e educacionais - para a compreensão histórica das diferenças e dos mecanismos explícitos e implícitos de exclusão educacional e social, como elementos justificadores das desigualdades sociais, em especial, da acumulação privada dos meios de produção e a exploração do homem pelo homem -, seus resultados poderão ser o acirramento dos estigmas e preconceitos para com a PD, visto que, ao mesmo tempo em que os governos brasileiros (federal, estadual e municipal) implementam uma política nacional fundamentada no princípio da diferença e no respeito ao tempo de aprendizagem de cada aluno, também implementam uma política de avaliação educacional, que padroniza as avaliaçóes e as expectativas de resultados dos alunos.

Por tudo isso, afirmamos a necessidade de uma mudança radical na organicidade da escola (seus tempos, espaços, relaçóes de poder, trato com conhecimento), ao mesmo tempo em que se constitua uma educação geral, com uma nova visão de mundo, homem e sociedade, amparados em mudanças estruturais da organização social mais ampla, para que, dessa forma, 
aumentem as oportunidades de acesso, permanência e sucesso educacional e social de todas as pessoas, inclusive as PD.

Apesar das limitações deste trabalho, esperamos que ele contribua para a área de Educação Física e, quiçá, para educadores em geral, no sentido de suscitar reflexôes acerca do trabalho pedagógico presente nos CAP/ Ifes, no intuito de estes virem a materializar práticas inclusivas em suas intervençôes. Também, que o potencial inovador face à constituição do seu quadro docente e que as condiçôes de trabalho sejam mais bem aproveitadas nos momentos de formulação de políticas educacionais formais, antes de serem massificadas e generalizadas para todas as escolas do país.

Porém, mais pesquisas sobre o assunto devem ser realizadas no sentido de investigar qual a situação vivenciada pelas PD nas diversas escolas do Brasil e nas diversas áreas do conhecimento. Isso para que, conforme sugere Sanfelice (2006), a partir de determinaçóes subjetivas, consigamos coletivamente programar açóes objetivas que superem práticas retrógradas (explícitas ou implícitas), que aumentam a exclusão educacional e social das novas geraçóes.

\section{Referências}

BERTO, R. C.; SILVA, M. G. C. Inclusão escolar: um olhar sobre a prática pedagógica em Educação Física. In: Congresso Brasileiro de Ciências do Esporte - Conbrace, $14^{\circ}, 2005$. Porto Alegre. Anais eletrônicos do XIV Conbrace, Porto Alegre, 2005.

BRACHT, V.; SOARES, F. R. A Educação Física nas práticas e nos discursos "inclusivos": um paradoxo chamado inclusão escolar. In: Congresso Brasileiro de Ciências do Esporte - Conbrace, 14º 2005. Porto Alegre. Anais eletrônicos do XIV Conbrace, Porto Alegre, 2005.

BRASIL. Ministério da Educação. Secretaria de Educação Especial. Política Nacional de Educaçáo Especial na Perspectiva da Educaçáo Inclusiva. Brasília: MEC/SEESP, 2008.

CARMO, A. A. do. Deficiência Física: A Sociedade Brasileira Cria, "Recupera” e Discrimina. 2. ed. Brasília: Secretaria dos Desportos/PR, 1991. . Inclusão escolar: roupa nova em corpo velho. Revista Integração, Brasília, v. 13, n. 23, p.43-47, 2001. 
CHICON, J. F. Educação física inclusiva na escola: construindo caminhos. In: Congresso Brasileiro de Ciências do Esporte - Conbrace, 14º 2005. Porto Alegre. Anais eletrônicos do XIV CONBRACE, Porto Alegre, 2005.

CONSELHO Nacional de Dirigentes das Escolas Básicas vinculadas às Instituiçóes Federais do Ensino Superior - Condicap. Forma de ingresso de alunos nas unidades de Colégios de Aplicação das IFES. Brasília: Condicap, 2007.

CRUZ, G. de C. Formação continuada de professores de Educação Física em ambiente escolar inclusivo. 2005. 229f. Tese (Doutorado em Educação Física) - Faculdade de Educação Física, Universidade Estadual de Campinas, 2005.

. Organização de ambientes inclusivos em aulas de Educação Física. In: Congresso Brasileiro Multidisciplinar de Educação Especial - CBMEE, 4º, 2007. Londrina. Anais eletrônicos do IV CBMEE, Londrina, 2007.

FALKENBACH, A. P.; WERLE, V.; e DREXSLER, G. A escola e a Educação Física diante da inclusão. In: Congresso Brasileiro de Ciências do Esporte - Conbrace, 15², 2007. Recife. Anais eletrônicos do XV CONBRACE, Recife, 2007.

FREITAS, L. C. de. A internalização da exclusão. Educação e Sociedade. Campinas, v. 23, n. 80, p. 299-325, 2002.

OLIVEIRA, F. F. de. Dialogando sobre educação, Educação Física e inclusão escolar. Revista Digital, Buenos Aires, año 8, n. 51, ago. 2002. Disponível em:<http://www.efdeportes.com/efd51/educa1.htm>. Acesso em: 24 out. 2011.

SANFELICE, J. L. Inclusão educacional no Brasil: limites e possibilidades. Revista de Educação/PUC-Campinas, Campinas, n. 21, p. 29-40. nov., 2006.

SEABRA JR., L. Inclusão, Necessidades Especiais e Educação Física: considerações sobre a ação pedagógica no ambiente escolar. 2006. 111f. Dissertação (Mestrado em Educação Física) - Faculdade de Educação Física, Universidade Estadual de Campinas, Campinas, 2006.

SILVA, R. H. dos R.; SOUSA, S. B. e VIDAL, M. H. C. Dilemas e perspectiva da Educação Física diante do paradigma da inclusão. Revista Pensar a Prática. Goiânia, v. 11, n. 2, p. 125-135, maio/ago. 2008. 
SOUSA, S. B. A. Inclusão escolar e o portador de deficiência nas aulas de educação física das redes municipal e estadual de Uberlândia-MG. 2002. 128f. Dissertação (Mestrado em Educação) - Universidade Federal de Uberlândia, Uberlândia, 2002.

SOUZA, W. C. A inclusão do educando com deficiência na escola pública municipal de Goiânia: o discurso dos professores de Educação Física. 2003. 114f. Dissertação (Mestrado em Educação Física) - Faculdade de Educação Física, Universidade Estadual de Campinas, Campinas, 2003.

VIDAL, M. H. C. V. Atando nós que constroem redes... A expansão da rede Pitágoras no contexto da transnacionalização da educação. 2006. 159 f. Dissertação (Mestrado em Educação) - Universidade Federal de Uberlândia, Uberlândia, 2006.

Recebido em: 7 nov. 2011.

Aceito em: 18 abr. 2012. 